\title{
Epidemiology of occupational exposure to needlestick and body fluids among doctors and medical students in Rafsanjan University of Medical Sciences
}

\author{
Rezaeian $\mathrm{M}, \mathrm{PhD}^{1^{*}}$, Asadpour $\mathrm{M}, \mathrm{PhD}^{2}$, Khademrezaeian $\mathrm{H}^{3}$ \\ 1. Professor, Dept. of Social Medicine, School of Medicine, Occupational Environmental Research Center, Rafsanjan \\ University of Medical Sciences, Rafsanjan, Iran. 2. Assistant Professor of Health Education. Social Medicine \\ Department. Rafsanjan Medical School. 3- Medical student. Rafsanjan Medical School
}

\begin{abstract}
Received: October 2011, Accepted: December 2011

Background: Health care workers occupationally are exposed to blood and other body fluids which might increase their risk of acquiring blood-borne pathogens and psychological stress. The aim of the present study was to determine the lifetime occupational exposure to needlestick injuries and body fluids among doctors and medical students in Rafsanjan University of Medical Sciences (2009).

Materials and methods: In this descriptive study, 100 doctors and medical students were asked to complete a valid and reliable self-reporting questionnaire regarding their lifetime occupational exposure to needlestick and body fluids. Data were analysed using SPSS. T-test and Chi-square test were used to compare the groups.

Results: The results highlighted that $57(60 \%)$ of the respondents had at least one lifetime occupational exposure to needlestick and 45 persons (48.4\%) had exposure to body fluids. However, only in $30(31.5 \%)$ cases the event was reported to the appropriate authorities. The highest number of needlestick injuries occurred within the emergency departments $(n=29,51 \%)$, during nightshift $(n=29,51 \%)$, and with suture needle $(n=37,65 \%)$.

Conclusion: Occupational exposures to needlestick and body fluids among doctors and medical students in our study have occurred with a relatively high lifetime incidence. Improving medical attentions might have positive effects on decreasing the incidence and prevalence of these constant occupational threats.
\end{abstract}

Key words: epidemiology, occupational exposure, needlestick, body fluids, doctors, medical students, Rafsanjan University of Medical Sciences.

\section{Introduction}

Doctors, nurses, and medical and nursing students are among the health care workers (HCW) who are occupationally exposed to blood and other body fluids (e.g. saliva, vomit, mucus, etc.) which might increase their risk of acquiring blood-borne pathogens especially human immunodeficiency virus (HIV), hepatitis C (HCV), hepatitis B (HBV), and psychological stresses. There are different studies which have investigated these types of exposures in the various settings [1-5]. Amonghealth care workers, evidences suggest that different health discipline students are also at a high risk of being occupationally exposed to needlestick injuries (NSI) and body fluids [6]. There are also a number of studies that have determined such occupational exposures among these high risk groups especially nursing [7-9] and medical [10-13] students. It should be noted that almost all the previous

\footnotetext{
" corresponding author: Mohsen Rezaeian, School of Medicine, Occupational Environmental Research Center, Rafsanjan University of Medical Sciences, Rafsanjan, Iran.

E-mail: moeygmr2@yahoo.co.uk
} 
studies had measured needlestick injuries or body fluids exposure (BBE) in the prior year of their study, also, there is no reported study which has investigated these important issues among doctors and medical students in Rafsanjan University of Medical Sciences (RUMS). RUMS has been established nearly three decades ago in a city called Rafsanjan in the Southeast of Iran (Figure 1). This school has three affiliated hospitals (i.e. AliEben-Abitaleb, Moradi and Niknafs) in which medical students spent their internship period.

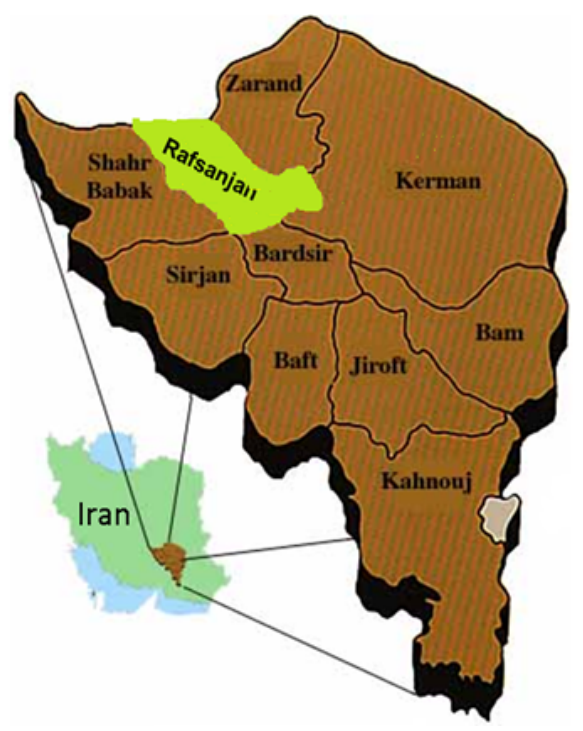

Figure 1: Study location in Iran

The aim of the present study was to determine the lifetime occupational exposure to needlestick and body fluids among doctors and medical students in RUMS.

\section{Materials and methods}

This descriptive study was carried out in the year 2009 within three affiliated hospitals of RUMS. A group of one hundred respondents including $25 \%$ of the random sample of total doctors $(n=25)$ and $100 \%$ of medical students $(n=75)$ were asked to complete a selfadministered questionnaire regarding their lifetime occupational exposure to needlestick injuries and fluids. The questionnaire consisted of three sections: 1) demographic characteristics of the participants including age, gender, work history and job (i.e. doctors or medical students), 2) their Hepatitis B vaccination history and 3) the details of their lifetime occupational exposure to needlestick or/and body fluids. Participants were also asked whether they usually recapped the used needles or not, and whether they had reported their exposure to the appropriate authorities.

The validity of the questionnaire was supported by reviewing the existing questionnaires. Furthermore, for assessing the reliability of the questionnaire a pilot study was also carried out. The questionnaires were handed out in all the departments and the participants were asked to complete them only if they were willing to. The completed questionnaires were gathered the next day and the data were entered into SPSS (version 16) and were analysed using Fisher's Exact and Student ttests, as well as Chi-square test.

\section{Results}

Ninety five completed questionnaires were returned giving the response rate as $95 \%$. The results highlighted that the mean age of doctors and students under study were $33.95 \pm 9.55$ and $25.20 \pm 1.65$ years, respectively. The mean of working months for doctors and students under study were $92.29 \pm 103.49$ and 7.52 \pm 6.06 , respectively. Demographical characteristics along with NSI and BFE of doctors and students under study are depicted in Table 1 . As the table shows, 15 (\%15.8) of doctors and $42(\% 44.2)$ of students had NSI $(\mathrm{P}=0.098)$ and13 (\%14) of doctors and 32(34.4) of students had BFE $(\mathrm{P}=0.044)$. 
Table 1. Some characteristics of the respondents based on their job

\begin{tabular}{|c|c|c|c|c|c|}
\hline \multirow[b]{3}{*}{ Variabl } & & \multicolumn{2}{|c|}{ Job } & \multirow[b]{2}{*}{ Total } & \multirow{3}{*}{$\begin{array}{c}\text { Fisher's } \\
\text { Exact Test }\end{array}$} \\
\hline & & Doctors & Students & & \\
\hline & & Number (\%) & Number (\%) & Number (\%) & \\
\hline \multicolumn{6}{|l|}{ Age } \\
\hline & Under 26 & $5(5.4)$ & $45(48.9)$ & $50(54.3)$ & \multirow{2}{*}{$P=0.003$} \\
\hline & 26 and above & $15(16.3)$ & $27(29.4)$ & $42(45.7)$ & \\
\hline \multicolumn{6}{|l|}{ Gender } \\
\hline & Male & $9(9.7)$ & $25(27.2)$ & $36(36.9)$ & \multirow{2}{*}{$P=0.27$} \\
\hline & Female & $11(12.0)$ & $47(51.1)$ & $58(63.1)$ & \\
\hline \multicolumn{6}{|l|}{ NSI* } \\
\hline & Yes & $15(15.8)$ & $42(44.2)$ & $57(60)$ & \multirow{2}{*}{$\mathrm{P}=0.098$} \\
\hline & No & $5(5.3)$ & $33(34.7)$ & $38(40)$ & \\
\hline \multicolumn{6}{|l|}{ BFE** } \\
\hline & Yes & $13(14)$ & $32(34.4)$ & $45(48.4)$ & \multirow{2}{*}{$P=0.044$} \\
\hline & No & $6(6.4)$ & $42(45.2)$ & $42(51.6)$ & \\
\hline
\end{tabular}

* Needlestick injuries

** Body fluids exposure

As a result, $57(60 \%)$ of all the respondents had at least one lifetime occupational exposure to needlestick injuries and 45 (48.4\%) had at least one lifetime occupational exposure to body fluids. As this table and other tables in this section depict the completed questionnaires had also some missing items. The highest number of needlestick injuries occurred within the emergency department $(n=29,51 \%)$, during nightshift $(\mathrm{n}=29,51 \%)$ and with suture needle $(\mathrm{n}=37,65 \%)$ and only $30(31.5 \%)$ of the exposed cases had reported their exposure to the appropriate authorities.

Furthermore, 91 (96\%) of the participants had received their Hepatitis B vaccinations and $43(45 \%)$ of the participants reported that they always recapped used needles. Among other variables under study i.e. age, gender, job, work history and recap practicing, only two have shown the significant association with the exposure to needlestick injuries and body fluids. First, recap practicing has significantly increased the exposure to needlestick injuries $(\mathrm{P}=0.001)$ (Table 2).

Table 2. The association between practising recap with exposure to needlestick injuries among respondents

\begin{tabular}{|c|c|c|c|}
\hline \multirow[b]{3}{*}{$\begin{array}{c}\text { Needlestick } \\
\text { injuries }\end{array}$} & \multicolumn{2}{|c|}{ Recap } & \multirow[b]{2}{*}{ Total } \\
\hline & Yes & No & \\
\hline & $\begin{array}{c}\text { Number } \\
(\%)\end{array}$ & $\begin{array}{c}\text { Number } \\
(\%)\end{array}$ & $\begin{array}{c}\text { Number } \\
(\%)\end{array}$ \\
\hline Yes & 39 (90.7) & $16(57.1)$ & $55(77.5)$ \\
\hline No & $4(9.3)$ & $12(42.9)$ & $16(22.5)$ \\
\hline Total & $43(100)$ & $28(100)$ & $71 *(100)$ \\
\hline
\end{tabular}

Chi-Square $=3.399, \mathrm{df}=1, \mathrm{P}=0.001$

* The complete data on joint distribution of two variables were available for 71 out of 95 cases.

The second variable was respondent's gender as being male also significantly increased the 
exposure to body fluids $(\mathrm{P}=0.005)$ (Table $3)$.

Table 3. The association between gender with exposure to body fluids among respondents

\begin{tabular}{|c|c|c|c|}
\hline \multirow[b]{2}{*}{ Body fluids } & \multicolumn{2}{|c|}{ Gender } & \multirow[b]{2}{*}{$\begin{array}{c}\text { Total } \\
\begin{array}{c}\text { Number } \\
(\%)\end{array}\end{array}$} \\
\hline & $\begin{array}{c}\text { Male } \\
\text { Number } \\
(\%)\end{array}$ & $\begin{array}{c}\text { Female } \\
\text { Number }(\%)\end{array}$ & \\
\hline Yes & $23(67.6)$ & $21(37.5)$ & 44 (48.9) \\
\hline No & $11(32.4)$ & $35(62.5)$ & $46(51.1)$ \\
\hline Total & $34(100)$ & $56(100)$ & $\begin{array}{c}90 * \\
(100)\end{array}$ \\
\hline
\end{tabular}

Chi-Square $=7.695, \mathrm{df}=1, \mathrm{P}=0.005$

* The complete data on joint distribution of two variables were available for 90 out of 95 cases.

\section{Discussion}

The results of the present study revealed that $60 \%$ of the respondents had at least one lifetime occupational exposure to needlestick, which is close to the $67.9 \%$ that was reported by Hanafi et al, in 2011 [1]. Nevertheless, our figure was substantially higher than 34\% that was reported by Salzer et al [10]; and $30.9 \%$ that was reported by Tadesse and Tadesse [2]; 49\% that was reported by Talas [9]; $31.4 \%$ that was reported by Wicker et al. [4] and 27\% that was reported by Adegboye et al. [5]. Similarly, $48.4 \%$ of our respondents had at least one lifetime occupational exposure to body fluids, which seems to be substantially higher than $23.1 \%$ that was reported by Kessler et al. [6]. It should be noted again that almost all the previous studies measured needlestick injuries in the previous year of their study, while in this study we measured lifetime exposure.

This might partially explain why we have determined a higher exposure than most of the other studies. Higher exposure to needlestick and body fluids in our study might also be due to less working experience of our respondents, especially among the medical students. Evidences also suggest that our respondents have a high workload, therefore, it seems that more studies are needed to determine the related factors. Based on these findings, it is recommended that further studies also try to measure lifetime exposure to determine a complete picture of these occupationally constant threats. Since such adverse events are always remembered by the affected population because of their possible considerable health consequences and psychological stress, we think that recall bias is unlikely to occur in the studies that measure lifetime exposure.

One of the other important findings of our study is that $68.5 \%$ of the exposed cases did not report their exposure to the appropriate authorities. This figure is much higher than $33.0 \%$, the proportion that was reported by Kessler et al study in 2011 [6], and 34\% reported by Salzer et al in 2011 [10]. The results of our study in accordance with the results of other studies [6-10] have determined that usually exposed cases do not report their exposure due to the following reasons: believing that their contact is not important; being too busy; not knowing how to report and/or believing that such reports might have an unfavorable effect on their job success. Therefore, such inappropriate attitudes and behaviors should be changed by improving medical curricula and/or conducting educational campaigns. We have also found that recap practicing has significantly increased the risk of exposure to needlestick. This finding has also been supported by previous studies [14-16].

In order to prevent this risky behavior, improving medical curricula and/or conducting educational campaigns are also needed. The aims of such programs are either 
to diminish such risky behaviors altogether or to implement single-handed "scoop" method to recap needles. Similarly, providing safety devices for the disposal of needles are also recommended [17].

The other important finding of our study is that the risk of exposure to needlesticks is higher in the emergency departments and during nightshifts. This could be due to the fact that usually emergency departments and nightshifts suffer from higher workload and inadequate staffing. The results of the previous studies also highlighted that sufficient staffing on every shift and extra caution throughout periods of high workload are needed to avoid exposure to needlesticks [18-20]. Our results also highlighted that $96 \%$ of our participants had been vaccinated against hepatitis B, which seems to be higher than $67.7 \%$ that was reported by Talas in 2009 [9]. It is therefore recommended that before beginning clinical practice in RUMS all medical students and doctors receive full immunization against hepatitis B. Finally, as in the Vaz et al study [3], we would like to recommend establishing a monitoring system which would provide precise information on the scale and trends of exposure to needlestick and body fluids in doctors, medical students, and other health care workers of RUMS. Launching such monitoring systems would also offer an environment for implementing the effective intervention.

\section{Conclusion}

Occupational exposures to needlestick injuries and body fluids among doctors and medical students in RUMS have occurred with a relatively high lifetime incidence. Improving medical curricula, conducting educational campaigns, increasing recap needles behaviour, implementation of safety devices and reducing the workload of the population under study might have positive effects on decreasing the incidence and prevalence of these constant threats.

\section{Acknowledgments}

This paper is based on Hamed Khadem Rezaeian medical thesis, which was supervised by Drs Mohsen Rezaeian and Mohammad Asadpour. The authors would like to thank all the doctors and medical students who participated in this study.

\section{Conflict of interest: Non declared}

\section{References}

1. Hanafi MI, Mohamed AM, Kassem MS, Shawki M. Needlestick injuries among health care workers of University of Alexandria Hospitals. East Mediterr Health J 2011; 17(1):26-35.

2. Tadesse M, Tadesse T. Epidemiology of needlestick injuries among health-care workers in Awassa City, Southern Ethiopia. Trop Doct 2010; 40(2):111-3.

3. Vaz K, McGrowder D, Crawford T, AlexanderLindo RL, Irving R. Prevalence of injuries and reporting of accidents among health care workers at the University Hospital of the West Indies. Int J Occup Med Environ Health 2010; 23(2):133-43.

4. Wicker S, Jung J, Allwinn R, Gottschalk R, Rabenau HF. Prevalence and prevention of needlestick injuries among health care workers in a German university hospital. Int Arch Occup Environ Health 2008; 81(3):347-54.

5. Adegboye AA, Moss GB, Soyinka F, Kreiss JK. The epidemiology of needlestick and sharp instrument accidents in a Nigerian hospital. Infect Control Hosp Epidemiol 1994; 15(1):2731.

6. Kessler CS, McGuinn M, Spec A, Christensen J, Baragi R, Hershow RC. Underreporting of blood and body fluid exposures among health care students and trainees in the acute care 
setting: a 2007 survey. Am J Infect Control 2011; 39(2):129-34

7. Hambridge K. Needlestick and sharps injuries in the nursing student population. Nurs Stand 2011; 25(27):38-45.

8. Karadag M. Occupational exposure to blood and body fluids among a group of Turkish nursing and midwifery students during clinical practise training: frequency of needlestick and sharps injuries. Jpn J Nurs Sci 2010; 7(2):12935.

9. Talas MS. Occupational exposure to blood and body fluids among Turkish nursing students during clinical practice training: Frequency of needlestick/sharp injuries and hepatitis B immunisation. J Clin Nurs 2009; 18(10):1394403.

10. Salzer HJ, Hoenigl M, Kessler HH, Stigler FL, Raggam RB, Rippel KE \& et.al. Lack of riskawareness and reporting behavior towards HIV infection through needlestick injury among European medical students. Int J Hyg Environ Health 2011; 214(5):407-10.

11. Sarraf-Yazdi S, Koong HN. Procedural safety: a hands-on course for medical students. Med Educ 2011; 45(5):512-3.

12. Merlin JS, Morrison G, Gluckman S, Lipschik G, Linkin DR, Lyon S \&et.al. Blood and body fluid exposures among US medical students in Botswana. J Gen Intern Med 2011; 26(5):5614.
13. Askew SM. Occupational exposures to blood and body fluid: a study of medical students and health professions students in Virginia. AAOHN J 2007; 55(9):361-71.

14. Moro PL, Moore A, Balcacer P, Montero A, Diaz D, Gómez V \& et.al. Epidemiology of needlesticks and other sharps injuries and injection safety practices in the Dominican Republic. Am J Infect Control 2007; 35(8):5529.

15. Aiken LH, Sloane DM, Klocinski JL. Hospital nurses' occupational exposure to blood: prospective, retrospective, and institutional reports. Am J Public Health 1997; 87(1):103-7.

16. Ingram J. Avoiding the risk of needlestick injuries. Nurs Stand 1993; 7(17):25-8.

17. Leiss JK. Management practices and risk of occupational blood exposure in U.S. paramedics: Needlesticks. Am J Ind Med 2010; 53(9):866-74.

18. Patrician PA, Pryor E, Fridman M, Loan L. Needlestick injuries among nursing staff: association with shift-level staffing. Am J Infect Control 2011; 39(6):477-82.

19. Olds DM, Clarke SP. The effect of work hours on adverse events and errors in health care. $\mathrm{J}$ Safety Res 2010; 41(2):153-62.

20. Clarke SP, Sloane DM, Aiken LH. Effects of hospital staffing and organizational climate on needlestick injuries to nurses. Am J Public Health 2002; 92(7):1115-9. 